Dialectologia. Special issue, IX (2021), 69-95.

ISSN: 2013-2247

Received 18 February 2021.

Accepted 1 March 2021.

\title{
DE USUREROS, CORNUDOS Y GLOTONES \\ EN EL LÉXICO CATALÁN RECOGIDO POR EL ALPI ${ }^{1}$
}

\author{
JOAN FONTANA i TOUS \\ Universitat de Barcelona * \\ joan_fontana@ub.edu
}

\section{Resumen}

Entre las diferentes designaciones de tipos humanos incluidos en el Cuestionario II, que trata las informaciones de tipo léxico, del Atlas Lingüístico de la Península lbérica $(A L P I)$, nos detendremos en las denominaciones para el usurero (núm. 729), el cornudo (núm. 731) y el glotón (núm. 734) en el dominio lingüístico catalán, así como en el castellano de tierras valencianas; es decir, en Cataluña, Valencia, Baleares, Aragón, el Rosellón y Andorra; en total, 111 puntos de encuesta que detallamos en el Apéndice. No cabe duda de que las variadas e ingeniosas formulaciones recabadas para estos tres tipos humanos ponen de manifiesto el incALCulable valor histórico y lexicográfico del ALPI.

\section{Palabras clave}

geolingüística, Atlas Lingüístico de la Península Ibérica $(A L P I)$, catalán, léxico, tipos humanos

\footnotetext{
${ }^{1}$ Este artículo se ha realizado en el marco del subproyecto PGC2018-095077-B-C43, "Variación y cambio lingüístico en catalán: análisis y comparación desde las perspectivas geolingüística y lexicográfica dialectal (GEO-LEX-CAT)", que forma parte, a su vez, del proyecto coordinado "El Atlas Lingüístico de la Península Ibérica: edición digital y análisis de datos (ALPI: EDA)". Agradecemos a Maria-Reina Bastardas, Joan Fontana Figuerola y José Enrique Gargallo sus siempre valiosas sugerencias, y a Eloi Bellés, Aline Kunz y Maria-Pilar Perea la información facilitada.

* Departament de Filologia Clàssica, Romànica i Semítica. Secció de Filologia Romànica. Despacho P2.44. Gran Via de les Corts Catalanes, 585, 08007 Barcelona.
} 


\title{
ON THE USURERS, CUCKOLDS AND GLUTTONS
}

\section{IN THE CATALAN LEXICON COLLECTED BY THE ALPI}

\begin{abstract}
Among the different designations of human types included in Questionnaire II, centred on lexical information, of the Atlas Lingüístico de la Península Ibérica (ALPI), we will focus on the denominations for the usurer (no. 729), the cuckold (no. 731) and the glutton (no. 734) in the Catalan linguistic domain, as well as in the Spanish-speaking area of Valencia; that is, in Catalonia, Valencia, the Balearic Islands, Aragon, Roussillon and Andorra; in total, 111 survey points that we list in the Appendix. There is no doubt that the varied and witty formulations collected for these three human types show the incALCulable historical and lexicographical value of the $A L P I$.
\end{abstract}

\section{Keywords}

geolinguistics, Atlas Lingüístico de la Península Ibérica $(A L P I)$, Catalan, lexicon, human types

\begin{abstract}
"Con el mismo criterio que un geólogo parte de su situación actual sobre la corteza terrestre y por sondeos cada vez más hondos pretende trazar la historia de nuestro planeta, así el lingüista se va adentrando poco a poco, y desde su posición de dialectólogo, hasta las fraguas mismas donde se elaboraron los usos lingüísticos" (Alvar 1951: 10)
\end{abstract}

\section{Introducción}

Los redactores de un atlas, así como todos aquellos que, posteriormente, nos beneficiamos de los datos por ellos recabados, compartimos la intuición de González (1992: 170) al comparar la lengua con "una «energeia», ${ }^{2}$ un ente que está en continua ebullición y transformación"; precisamente es en ese aspecto donde se pone de relieve el papel de los atlas lingüísticos, siendo ellos los verdaderos amanuenses de la crónica de un tiempo, asociado a un espacio en el que, por su extensión, resulta posible registrar, y establecer, la diferenciación diatópica de una realidad lingüística. En este sentido, el Atlas Lingüístico de la Península Ibérica (ALPI, a partir de ahora) se convierte

\footnotetext{
${ }^{2}$ Término de origen griego ( $\dot{\varepsilon} v \varepsilon ́ \rho \gamma \varepsilon \iota \alpha$ ), fundamental en la doctrina aristotélica, que indica algo cuya esencia tiende a su fin.
} 
Dialectologia. Special issue, IX (2021), 69-95.

ISSN: 2013-2247

en "una especie de acta documental del carácter y fisonomía del habla popular de la Península en los años inmediatamente anteriores a la guerra civil”33 (Navarro Tomás 1975: 14).

\section{Objeto de estudio}

Dentro del tesoro léxico que nos brinda la urdimbre del $A L P I$, centraremos nuestra atención en las zonas catalanohablantes, ${ }^{4}$ cuyas encuestas estuvieron a cargo de dos grandes lingüistas como Francesc de Borja Moll ${ }^{5}$ (1903-1991) y Manuel Sanchis Guarner (1911-1981). Dicho espacio comprende 111 puntos de encuesta, ${ }^{6}$ ubicados en Andorra (1), Aragón (7), Baleares (13), Cataluña (42), el Rosellón (7) y Valencia (41); y cuyos materiales convendría advertir que todavía no se han transcrito en su totalidad, pues el $A L P I$, a día de hoy, sigue siendo un proyecto en curso.

En cuanto al objeto de nuestro estudio, ${ }^{7}$ vaya por delante una consideración

\footnotetext{
${ }^{3}$ En lo que atañe a los puntos del dominio catalán, en el momento de estallar la guerra civil española faltaban por completar las encuestas de algunos lugares de los Pirineos y el Rosellón, encuestas que se terminaron en 1947 y 1952, respectivamente. Así pues, y a pesar de excepciones puntuales, los materiales catalanes, para decirlo con García Mouton (2012: 275), "son de una «sincronía» irreprochable", que, huelga decirlo, es la visión de la realidad lingüística que cualquier atlas pretende ofrecer.

${ }^{4}$ Cabe señalar que nuestro estudio también toma en consideración los quince puntos castellanohablantes de la Comunidad Valenciana: Castillo de Villamalefa, Fanzara, Teresa de Begís y Azuébar (Castellón); Ademuz, Tuéjar, Marinas, Caudete de las Fuentes, Pedralba, Godelleta, Dos Aguas, Teresa de Cofrentes y Anna (Valencia); y Monforte y Dolores (Alicante; ambos puntos encuestados, no por Moll y Sanchis Guarner, como resultaría preceptivo, sino, en 1932, por Aurelio M. Espinosa hijo y Lorenzo Rodríguez Castellano, responsables de Castilla). Apuntemos, finalmente, que en cuatro de estos puntos (Caudete de las Fuentes, Anna, Monforte y Dolores) no se registra ningún dato para las preguntas que nos interesan.

${ }^{5}$ Coautor, con Antoni Maria Alcover (1862-1932), del Diccionari català-valencià-balear (DCVB). No deberá, pues, extrañar al lector que las geolocalizaciones de ambas obras citadas en este trabajo, en gran parte, coincidan.

6 “El ALPI cubre toda la Península Ibérica e incluye asimismo el Rosellón (políticamente francés), el principado de Andorra y las Islas Baleares, territorios estos todos de lengua catalana. Excluye el valle de Arán, que habla un dialecto gascón (...) y los territorios ultramarinos de lengua catalana (Alguer)" (Colón \& Lüdtke 1965: 324). Véase el Apéndice para un listado detallado de la red de puntos de ámbito lingüístico catalán.

${ }^{7}$ Sírvanos de amparo la siguiente captatio benevolentiae a cargo de Sanchis Guarner (1953: 26): "Es verdad que el Atlas lingüístico es sólo un inventario incompleto del léxico de una serie de lugares separados, pero pone en orden y facilita la interpretación de grandes masas dialectales, y sobre todo el Atlas ofrece el panorama del total del dominio lingüístico, con la estructura de su conjunto y sus facetas
} 
previa: así como no nos sorprende que en el Cuestionario II del ALPI (dedicado a cuestiones léxicas) ${ }^{8}$ encontremos representadas cumplidamente las labores tradicionales más extendidas en el área peninsular y, en cambio, se haya prescindido, por citar solo tres ejemplos, de la nomenclatura correspondiente a cultivos o industrias regionales como el esparto (típico de la Mancha), el cáñamo (propio de Valencia y Murcia) o el arroz (tradicional de Tortosa y Valencia), ${ }^{9}$ se nos antoja igual de lógico que no se obvien los datos alusivos a la condición humana, a aquellos tipos humanos que, a causa de su reprobable comportamiento (o bien como consecuencia de la actuación no menos censurable de un tercero, en el caso del cornudo), devienen objeto de una crítica atención social, a menudo cargada de una acerada ironía.

En el citado cuestionario, se introducen los siguientes tipos humanos: el usurero (núm. 729), la ramera (núm. 730), el cornudo (núm. 731), el manirroto (núm. 731a), la coqueta (núm. 731b), el charlatán (núm. 731c), el bravucón (núm. 731d), el cobarde (núm. 731e), el borracho (731f), el glotón (núm. 734) y el papanatas (núm. 736). ${ }^{10}$ De los once anteriormente citados, nos ocuparemos de tres: el usurero (núm. 729), el cornudo (núm. 731) y el glotón (núm. 734); advirtamos que, a pesar de que "[e]n el Cuestionario léxico se adoptó la organización temática del AIS" (González 1992: 159), el usurero y el cornudo no aparecen en dicha obra, ${ }^{11}$ ni tampoco en el $A L F$ o el $A L C$, de manera que se trata de un par de afortunadas innovaciones, adoptadas por la mayoría de atlas posteriores ${ }^{12}$ (véanse, por ejemplo, el ALDC o el ALEANR). ${ }^{13}$

presentadas orgánicamente". No en vano, "la misión de los atlas ha sido siempre la de recoger la variación de la lengua en el espacio" (García Mouton 2007: 338).

8 "El Cuestionario del ALPI fue confeccionado por don Tomás Navarro con la cooperación de Amado Alonso y $[A ́$ ]ngel Lacalle, quienes trabajaron fundamentalmente a partir de los del ALF [Atlas linguistique de la France] y del AIS [Atlante italo-svizzero] en la parte dedicada al léxico" (González 1992: 156); no olvidemos, por otro lado, que "[e]l cuestionario de léxico [del ALPI] tiene un carácter etnolingüístico" (Sousa 2010: 244).

${ }^{9}$ De igual modo, "[p]odría parecer incluso absurdo que en Galicia se hicieran preguntas sobre los molinos de viento o sobre el cultivo del azafrán, que en cambio serán fundamentales en La Mancha" (González 1992: 160).

10 Términos como los anteriormente citados demuestran que "el ALPI hubiera podido llamarse Atlas lingüístico y etnográfico, como de hecho lo es, aunque no pareciera indispensable indicarlo en el título" (Navarro Tomás 1975: 12-13). Cfr., en la nota 8, Sousa (2010: 244).

${ }^{11}$ En cuanto al glotón, véase el mapa 718 del AIS, correspondiente a Un ghiottone.

12 "También es normal que, aunque vayan evolucionando, los cuestionarios de los atlas más recientes respeten un número importante de preguntas incluidas en otros atlas, porque eso asegura las posibilidades de comparación de los mapas que se redacten con los de atlas anteriores" (García Mouton 2007: 335).

${ }^{13}$ Véanse los mapas de referencia de ambas obras en las notas 16, 45 y 59. 
En el presente estudio, anotaremos las distintas voces registradas en el $A L P I$, a lo largo y ancho del dominio catalán, para denominar los tres tipos humanos objeto de nuestra indagación. Con tal propósito, al final de cada capítulo, nos serviremos de una tabla (una para el usurero, otra para el cornudo y una tercera dedicada al glotón), donde mostraremos con detalle la información léxica cosechada. ${ }^{14}$ Los resultados se dividirán por provincias (en el caso de Aragón, Cataluña y Valencia) o regiones (cuando se trate del Rosellón, Andorra y las Baleares); en la tabla, a la derecha del nombre de cada territorio, indicaremos entre paréntesis la suma de resultados obtenidos. En lo que atañe a la presentación de las informaciones léxicas en las tres tablas, los diferentes testimonios se mostrarán por orden de importancia, es decir, de mayor a menor representatividad en cada región (o provincia); sin embargo, cuando el número de resultados coincida para dos o más términos, optaremos por clasificarlos ALFabéticamente. Asimismo, para cada denominación, anotaremos entre paréntesis dos tipos de datos numéricos: en primer lugar, en negrita, los resultados obtenidos en dicha región (por tanto, un número solo); y, seguidamente, los puntos de encuesta (identificados mediante un código de localización de tres dígitos) ${ }^{15}$ en los que se ha registrado dicha designación. Recordemos, finalmente, que la lista con los 111 puntos que conforman la red de encuesta del ámbito catalanohablante se encuentra detallada en el Apéndice final.

2.1 Usurero (núm. 729; 167 resultados) ${ }^{16}$
El señor don Juan de Robres,
con caridad sin igual,
hizo este santo hospital
y también hizo los pobres.

\footnotetext{
${ }^{14}$ Tanto el objetivo como la extensión de este artículo nos han aconsejado prescindir de la transcripción fonética registrada en las fichas del Cuestionario. A pesar de ello, en ciertas ocasiones la ortografía de un término (por ejemplo, esplotador o bainyut, en vez de explotador o banyut, respectivamente) nos ofrecerá, de resultas, interesantes informaciones de carácter fonético.

${ }^{15}$ Véase el Apéndice.

${ }^{16}$ Véase el mapa 1812 (L'usurer) del $A L D C$ y, para la franja catalanohablante de Aragón, la lámina n.으 1.318 / mapa n.o 1.107 (Nombres que se dan al usurero) del ALEANR.
} 
He aquí el famoso epigrama, obra de Juan de Iriarte y Cisneros (1702 -1771), fácilmente asimilado por el repertorio popular "como expresión proverbial para aludir a los usureros arrepentidos, a los que antes de dedicarse a la caridad se afanaron por esquilmar al prójimo" (Iribarren 1994: 252). Al decir del refrán, Corazón de usurero negro como las entrañas de un tintero (Kleiser 1995: 708, núm. 61.742), o, según un verso de Ezra Pound (1885-1972), the beast with a hundred legs, USURA ['la bestia de cien patas, USURA'] (Canto XV, v. 21). No en balde, en el Inferno de Dante (Canto XVII) la usura se sitúa en el séptimo círculo, entre los pecados de maldad o antinaturales, es decir, aquellos en los que el hombre no peca por instinto sino valiéndose de la razón y con absoluta voluntariedad. ${ }^{17}$

El macrolema usurer (27 resultados; véase REW 9098; ALDC, mapa 1812; y compárese con el port. ${ }^{18}$ usurário, el esp. usurero, el fr. usurier, el it. usuraio o el rum. uzurar) se distribuye en las cuatro provincias catalanas, así como en Huesca, Teruel, Andorra y el Rosellón, donde registramos también la variante usurier (en Banyuls), que coincide con el correspondiente término francés. En cuanto al castellanismo usurero ${ }^{19}$ (13 resultados), se encuentra representado en los dos puntos de encuesta de Zaragoza (Mequinenza y Maella) y en Teruel (Valljunquera); en la zona valenciana, la citada forma usurero (10 resultados) se acompaña de hasta seis variantes (19 resultados); son, por orden de relevancia: $\operatorname{osurero}^{20}$ (6; Valencia y Alicante), surero (5; Valencia y Alicante), usorero (4; Castellón y Valencia), ausurero (en Moncofa, Castellón, y en Casinos, Valencia), asurero (en Quart de Poblet, Valencia) y esurero (en Marinas, Valencia, de habla castellana).

Destaquemos, asimismo, las expresivas denominaciones surgidas a partir de los conceptos 'escanyar' ['estrangular'] ${ }^{21}$ (DECat, s. v. canya, con el sentido de 'tràquea

\footnotetext{
${ }^{17}$ La celebérrima capilla paduana de los Scrovegni, decorada por Giotto, y convertida en indiscutible obra maestra del arte occidental, fue erigida a principios del siglo xIV por Enrico degli Scrovegni con el fin de expiar la desmedida usura practicada por su padre Reginaldo (véase Inferno, Canto XVII, v. 64-75).

${ }^{18}$ Las abreviaturas utilizadas a lo largo del estudio corresponden a los siguientes romances: portugués (port.), español (esp.), francés (fr.), italiano (it.) y rumano (rum.).

${ }^{19}$ El castellano logrero, "Persona que da dinero a logro" (DLE, s. v.), se circunscribe al área castellonense (La Pobla de Benifassà, catalanohablante, y Fanzara y Azuébar, castellanohablantes). Del antiguo catalán llogre (< “del II. LǔCRUM 'guany, profit'” [DECat, s. v.]), derivaría llogrer ['creditor'].

${ }^{20}$ Se trata de la forma más habitual de Alicante, registrada en Biar, Benilloba y Guardamar.

${ }^{21}$ Mención aparte merece el hápax estrenyacorbatins (en Besalú, Gerona), que cambia la soga por un igualmente letal corbatí (cfr. it. cravattaio, en sentido propio, 'fabricante de corbatas'. Cfr. también la
} 
artèria'; cfr. it. strozzino < strozzare), 'espellar' ['despellejar'] (cfr. it. scortichino < scorticare), 'penjar' ['colgar'] y 'matar', unidos al sustantivo pobres, convertido en la víctima propiciatoria de la acción referida en la primera parte. El término más frecuente es escanyapobres ${ }^{22}$ (36 resultados, es decir, un 21,5\% del total), que fue justamente el elegido por Narcís Oller $^{23}$ (1846-1930) para dar título a una de sus novelas más conocidas: L'Escanyapobres ${ }^{24}(1884)$; a excepción de Castellón, ${ }^{25}$ esta forma resulta la más habitual en todas las áreas donde aparece, es decir, en el Principado, ${ }^{26}$ en Andorra y en el Rosellón. Con el mismo trágico resultado, atestiguamos penjapobres en Moncofa (Castellón) y matapobres ${ }^{27}$ en Benabarre (Huesca) y en Benilloba (Alicante). El cruel martirio de San Bartolomé, ${ }^{28}$ la desolladura, se manifiesta en las siguientes formas, todas de ámbito valenciano: pelapobres (en Beniopa, Valencia), espellejapobres ${ }^{29}$ (DECat, s. v. pell; en Tuéjar, Valencia, de habla castellana) o espelejapobres, localizada en los castellanohablantes Castillo de Villamalefa (Castellón) y Ademuz (Valencia); por último, registramos sollejapobres (sollejar < eshollejar < deshollejar [cfr. DLE, s. v.]) en Teresa de Cofrentes (Valencia), también de habla castellana.

El término explotador (16 resultados), ${ }^{30}$ lo recogemos en las cuatro provincias de Cataluña, en las tres de la Comunidad Valenciana y en Zaragoza. La variante esplotador (5 resultados) aparece en Bell-lloc d'Urgell (Lérida), Molló (Gerona), Roda de Berà

conocida expresión, con un cariz económico, apretarse el cinturón, es decir, "Reducir los gastos por escasez de medios", según el DLE, s. v. cinturón).

${ }^{22}$ Localizamos la variante sin palatalización escanapobres en Pont de Suert, Senterada y Bassella (Lérida).

${ }^{23}$ A título anecdótico, señalaremos que escanyapobres también se encuentra en los cuatro puntos de encuesta de la provincia de Tarragona más próximos a Valls, ciudad nativa del autor. Nos referimos a Santa Coloma de Queralt, Vimbodí, Vila-seca de Solcina y Roda de Berà.

${ }^{24}$ Traducida al castellano, en 1897, como "El Esgaña-pobres" (trad. Rafael Altamira) y al francés, en 1899, como "Le Rapiat" (trad. Albert Savine).

${ }^{25}$ Localizado en Oropesa del Mar.

${ }^{26}$ Si bien es cierto que en Lérida usurer cuenta con diez registros, por los nueve de escanyapobres, es de justicia sumar a esta última forma la variante escanapobres, localizada en tres puntos de encuesta (cfr. nota 22).

${ }^{27}$ El DCVB lo registra, con el sentido de 'usurer', en Benilloba.

${ }^{28}$ En el Quijote (I, Cap. XXXI), para recalcar la fiereza de los azotes que Juan Haldudo propinó al pobre mozo Andrés, Cervantes apunta que lo dejó "hecho un Sambartolomé desollado".

${ }^{29}$ Con idéntica forma verbal, anotamos espellejavivos en Teresa de Cofrentes (Valencia), de habla castellana.

${ }^{30}$ Según Coromines (DECat, s. v. explosió): "Explotar és un gal-licisme arrelat en el sentit d"espletar, aprofitar a fons o abusivament', sense relació etimològica ni de cap mena amb explosió". 
(Tarragona), Cinctorres (Castellón) y Biar (Alicante). Explotador con pérdida de la /d/ intervocálica, es decir, explotaor, en Peñíscola y Aín (Castellón). En Turís (Valencia) documentamos esplotaor $\mathrm{y}$, finalmente, el participio de presente explotant, en Taurinyà (el Rosellón).

El carácter malvado de este tipo humano se manifiesta en el uso de términos tan connotados como esbirro ${ }^{31}$ ( $<$ it. sbirro; en Santa Coloma de Queralt, Tarragona), heretge $^{32}$ (< latín tardío HAERĚTĭcus; en Eivissa, Ibiza), cafre ${ }^{33}$ (en Bassella, Lérida), abusador $^{34}$ (en Sant Joan Baptista, Ibiza), estafador ${ }^{35}$ (en Benilloba y El Pinós, Alicante), usurpador $^{36}$ (en la castellanohablante Godelleta, Valencia) o lladre ${ }^{37}$ (< lat. LATRO; en València d’Àneu y Alàs, Lérida). Dentro de este grupo, dos formas resultan especialmente sugerentes: sangonella ${ }^{38}$ ['sanguijuela'] (DECat, s. v. sang; Bastardas 2018: 348; cfr. port. sanguessuga, it. sanguisuga o rum. lipitoare), ${ }^{39}$ en Rialb (Lérida), y jueu ${ }^{40}$ ['judío'] (< lat. JUDAEUS), en Llo (el Rosellón). En francés, no deja de sorprendernos la expresiva denominación fesse-mathieu ['verguea-mateo'], en alusión a aquellos usureros que dejan en mal lugar a San Mateo, quien, antes de convertirse en apóstol y evangelista, también pertenecía al gremio en cuestión. ${ }^{41}$

\footnotetext{
31 "Home mancat de sentiments humanitaris" (DCVB, s. v. esbirro²).

32 Vulgarmente, "Home cruel o de mala conducta" (DCVB, s. v. heretge ${ }^{2}$ ). Véase también DECat (s. v. heretge).

33 "Persona bàrbara, brutal” (DIEC, s. v. cafre ${ }^{2}$; cfr. port. cafre).

${ }^{34}$ Derivado de "Abusar 'usar malament, usar amb excés'” (DECat, s. v. ús).

${ }^{35}$ De la misma ralea, estafante (en Biar, Alicante) y estafant (en Vistabella del Maestrat, Castellón). Todos ellos derivados nominales de estafar: "del cast. germanesc estafar id., i aquest, de l'it. staffare 'treure els peus dels estreps', perquè l'estafat el deixen econòmicament en fals, com al qui munta en cavall, si li fan desestrebar els peus, i es queda en aquesta posició; staffare és derivat de l'it. staffa 'estrep', que prové del longobard *STAFFA 'petjada, pas'" (DECat, s. v. estafar).

${ }^{36}$ Derivado de usurpar, "del II. usurpare id., contracció d'un compost amb rapěre 'arrabassar"' (DECat, s. v. ús).

${ }^{37}$ En el capítulo 163 del Tirant lo Blanch, leemos una curiosa justificación antroponímica: "Tirant vol dir usurpador de béns o, més propi parlar, lladre".

${ }^{38}$ Van en el mismo sentido las caracterizaciones se beu la sang dels pobres (en Guardamar, Alicante) y se come la sangre de los pobres (en Teresa de Begís, Castellón). Pertenece a dicha esfera el humorístico refrán Se compadeció el logrero, y se metió a sanguijuelero (Kleiser 1995: 708, núm. 61.751). Nótese como, en italiano, el término vampiro puede usarse en el citado sentido.

${ }^{39}$ En la base del sustantivo rumano está el verbo de origen eslavo $a(\mathrm{se})$ lipi 'pegar(se), enganchar(se)'.

${ }^{40}$ En sentido figurado, "Home dolent, especialment l'avar o usurer, el qui no té pietat amb tal de guanyar diners" (DCVB, s. v. jueu $\left.{ }^{2}\right)$. También en el Rosellón, concretamente en Formiguera, se registra la forma juif (< fr. juif). No es este el momento de ahondar en la recurrente figura del usurero judío; baste pensar en el archiconocido Shylock de The Merchant of Venice.

${ }_{41}$ "[lesus] vidit hominem sedentem in teloneo, Matthaeum nomine, et ait illi: «Sequere me». Et surgens secutus est eum" ['[Jesús] vio a un hombre llamado Mateo, que estaba sentado en el lugar donde
} 
Dialectologia. Special issue, IX (2021), 69-95.

ISSN: 2013-2247

Cerramos este apartado con una serie de denominaciones más propias de otros ámbitos; el del egoísmo: egoisme (en Vilar de Canes, Castellón) y egoista ${ }^{42}$ (en Maella, Zaragoza; en Aspa y Mont-roig de Sió, Lérida; y en Ascó y Amposta, Tarragona); y, en segundo lugar, el de la avaricia: avaro (< lat. AVARUS; DECat, s. v. avar) en Santpedor y Sant Martí de Sesgueioles (Barcelona), en Roda de Berà (Tarragona) y en La Pobla de Benifassà (Castellón); avariciós (en Aguaviva, Teruel); garrepa ${ }^{43}$ (< esgarrapar ['arañar']; DECat, s. v. garra) en Santpedor (Barcelona); y gorromino ${ }^{44}$ (en Rafaelbunyol, Valencia).

\begin{tabular}{|c|c|}
\hline $\begin{array}{r}\text { Pregunta } \\
\text { Región }\end{array}$ & Usurero (núm. 729) \\
\hline Huesca (3) & usurer $(2 ; 613,614)$, matapobres $(1 ; 613)$ \\
\hline Zaragoza (5) & $\begin{array}{c}\text { explotador }(2 ; 628,629), \text { usurero }(2 ; 628,629), \\
\text { egoista }(1 ; 629)\end{array}$ \\
\hline Teruel (3) & usurer $(1 ; 634)$, usurero $(1 ; 633)$, avariciós $(1 ; 634)$ \\
\hline Andorra (2) & escanyapobres $(\mathbf{1} ; 700)$, usurer $(\mathbf{1} ; 700)$ \\
\hline Rosellón (9) & $\begin{array}{l}\text { escanyapobres }(\mathbf{3} ; \mathbf{7 0 2}, \mathbf{7 0 6}, \mathbf{7 0 7}) \text {, usurer }(\mathbf{2} ; \mathbf{7 0 3}, \mathbf{7 0 4}), \\
\text { explotant }(\mathbf{1} ; \mathbf{7 0 2}) \text {, jueu }(\mathbf{1} ; \mathbf{7 0 5}), \\
\text { juif }(\mathbf{1} ; \mathbf{7 0 1}), \text { usurier }(\mathbf{1} ; \mathbf{7 0 7})\end{array}$ \\
\hline Lérida (30) & 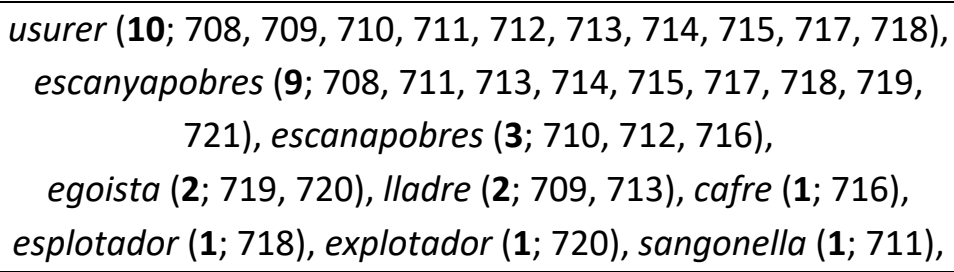 \\
\hline Gerona (13) & $\begin{array}{c}\text { escanyapobres }(\mathbf{8} ; \mathbf{7 2 2}, \mathbf{7 2 3}, \mathbf{7 2 5}, \mathbf{7 2 6}, \mathbf{7 2 7}, \mathbf{7 2 9}, \mathbf{7 3 0}, \mathbf{7 3 1}) \text {, } \\
\text { usurer }(\mathbf{2} ; \mathbf{7 2 9}, \mathbf{7 3 0}) \text {, esplotador }(\mathbf{1} ; \mathbf{7 2 4}) \\
\text { estrenyacorbatins }(\mathbf{1} ; \mathbf{7 2 7}) \text {, explotador }(\mathbf{1} ; \mathbf{7 3 1})\end{array}$ \\
\hline Barcelona (16) & $\begin{array}{c}\text { escanyapobres }(\mathbf{6} ; \mathbf{7 3 2}, \mathbf{7 3 4}, \mathbf{7 3 5}, \mathbf{7 3 7}, \mathbf{7 3 8}, \mathbf{7 3 9}) \text {, } \\
\text { usurer }(\mathbf{4} ; \mathbf{7 3 2}, \mathbf{7 3 8}, \mathbf{7 3 9}, \mathbf{7 4 0}) \text {, explotador }(\mathbf{3} ; \mathbf{7 3 3}, \mathbf{7 3 5}, \mathbf{7 3 7}) \text {, } \\
\text { avaro }(\mathbf{2} ; \mathbf{7 3 4}, \mathbf{7 3 6}) \text {, garrepa }(\mathbf{1} ; \mathbf{7 3 4})\end{array}$ \\
\hline
\end{tabular}

cobraba los impuestos para Roma, y le dijo: «Sígueme». Y se levantó y le siguió'] (Evangelium secundum Matthaeum IX, 9).

${ }^{42}$ Ambos términos, egoisme y egoista, "calcats del fr. égoïsme, -oïste [1755]" (DECat, s. v. jo).

43 "Avarut, excessivament afectat de guardar els diners" (DCVB, s. v. garrepa $\left.{ }^{2}\right)$.

${ }^{44}$ Castellanismo (DCECH, s. v. gurrumino) con el sentido de "Avar, escás" (DCVB, s. v. gorromino²). Registramos en Godelleta (Valencia), lugar de habla castellana, la variante gorrumino. 


\begin{tabular}{|c|c|}
\hline Tarragona (22) & $\begin{array}{c}\text { escanyapobres }(8 ; 741,742,743,744,745,746,748,749) \text {, } \\
\text { usurer }(5 ; 741,742,744,745,748) \text {, } \\
\text { explotador }(4 ; 742,745,747,748) \text {, egoista }(2 ; 743,749) \text {, } \\
\text { avaro }(1 ; 746) \text {, esbirro }(1 ; 741) \text {, esplotador }(1 ; 746)\end{array}$ \\
\hline Castellón (22) & 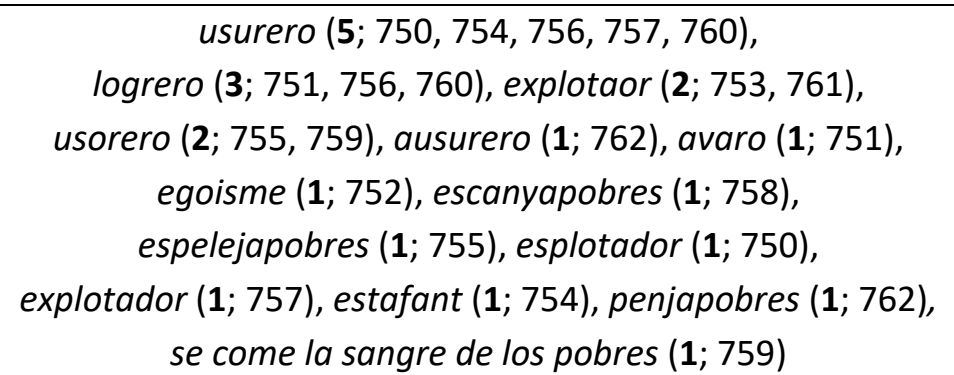 \\
\hline Valencia (26) & 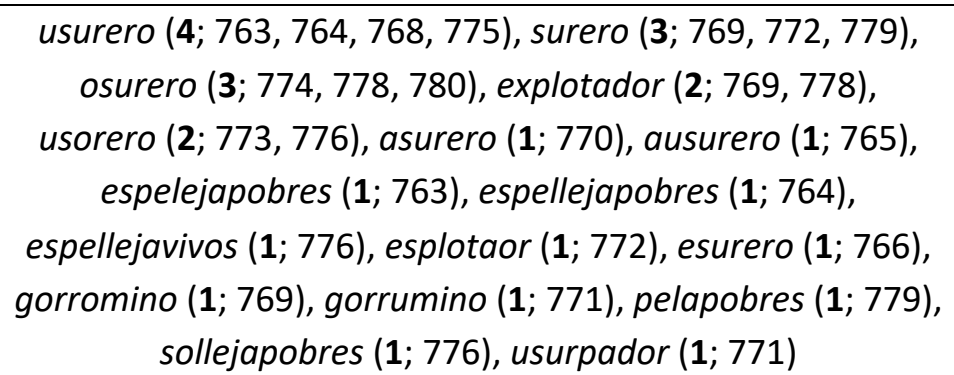 \\
\hline Alicante (14) & 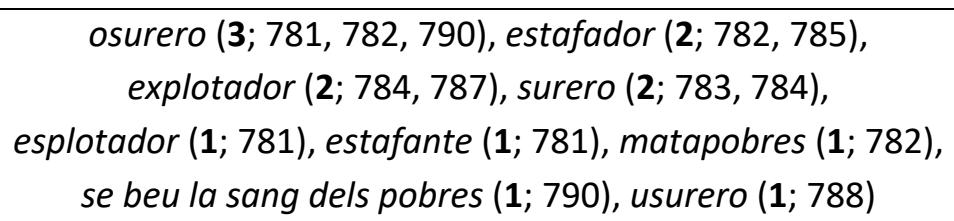 \\
\hline Baleares (2) & abusador $(1 ; 791)$, heretge $(1 ; 792)$ \\
\hline
\end{tabular}

Tabla 1. Resultados léxicos del ALPI para el usurero (núm. 729) en el dominio lingüístico catalán y en el castellano de tierras valencianas.

\subsection{Cornudo (núm. 731; 156 resultados) ${ }^{45}$}

La admiración que muchos ya sentíamos ante la plasticidad del cuadro La fragua de Vulcano (1630) se acentuó aún más al descubrir de dónde provenía la honda turbación que Velázquez plasmó en los rostros incrédulos de Vulcano y de sus diligentes cíclopes: un joven Apolo acababa de anunciarles que Marte, para quien trabajaban en ese preciso instante, se había acostado con Venus, esposa del "cornudo" Vulcano (cfr. Ovidio, Metamorphoses IV, v. 171-176). Así define el DLE (s. v. cornudo²) la condición del dios herrero: "Dicho de una persona, especialmente de un marido: Que es objeto de infidelidad por parte de su pareja".

\footnotetext{
${ }^{45}$ Véase el mapa 1813 (El cornut) del $A L D C$ y, para la franja catalanohablante de Aragón, la lámina n.은 1.323 / mapa n.o 1.112 (Nombres que se dan al cornudo) del ALEANR.
} 
Del total de 156 respuestas obtenidas para este tipo humano, cornut ${ }^{46}$ (24 resultados; "del II. CŏRnU" [DECat, s. v. corn]; cfr. port. cornudo, it. cornuto o rum. încornorat) y sus variantes (27) se distribuyen en todo el dominio a excepción de Andorra y Baleares. Destacaremos la variante diptongada cuernut (en Castellón, también qüernut), documentada en la Comunidad Valenciana, así como en Maella (Zaragoza). Por influencia de las lenguas vecinas, registramos el castellanismo cornudo ${ }^{47}$ en las provincias de Valencia y Castellón, y el galicismo cornart $(<\mathrm{fr}$. cornard), en Senet y València d'Àneu (Lérida), respectivamente.

Según el DCVB (s. v. cornut), “A moltes comarques és més freqüent la forma banyut". En efecto, banyut (33 resultados; DECat, s. v. banya) es la principal denominación en las cuatro provincias catalanas, Baleares ${ }^{48}$ y Andorra; se acompaña de las variantes banut, a partir de bana $^{49}$ (variante sin palatalización de banya ['cuerno']), localizada en Pont de Suert (DCVB, s. v. banut) y Senterada (Lérida), y bainyut, registrada en Vimbodí y Ascó (Tarragona). Vale la pena apuntar el epíteto que porta banyes, ${ }^{50}$ en Aspa (Lérida) y en Calp (Alicante), ${ }^{51}$ apéndice que corona tanto al marido engañado como al demonio (DECat, s. v. banya); a este último, con una diminutiva denominación afectuosa, también se le llama en Banyeta ${ }^{52}$ ['Cuernecito'].

46 "[De corn,] N'han quedat altres derivats, particularment cornut 'marit enganyat' [fi S. XIV, Eiximenis]" (DECat, s. v. corn).

${ }^{47}$ Cornuda y el apunte lleva cuernos, en los puntos castellanohablantes de Azuébar y Teresa de Begís (Castellón), respectivamente.

${ }^{48} \mathrm{~A}$ título anecdótico, citaremos el refrán Es darrer qui ho sap és es banyut, localizado por el DCVB (s. v. banyut) en Mallorca; téngase en cuenta que dicha paremia acostumbra a citarse en la forma estándar: $E I$ cornut és el darrer que ho sap (Parés 1999: 232, núm. 257); cfr. en Juvenal (IV, X, v. 342) Dedecus ille domus sciet ultimus ['Él será el último en saber el deshonor de su casa'].

49 "En català la forma bana és de les terres occidentals (Ribagorça, Pallars, Balaguer, Morella) (...) És sabut que en els resultats de -NN- hi ha hagut una vacil-lació entre $-n-\mathrm{i}-\eta-$ - (enganar $\mathrm{i}$ enganyar, cabana $\mathrm{i}$ cabanya), essent la - $n$ - més aviat la solució dels parlars pirinencs" (DECat, s. v. banya).

${ }^{50} \mathrm{El}$ apunte que les porta llargues, localizado en Santpedor (Barcelona), omite el referente nominal banyes. No olvidemos que este sustantivo forma parte del conocido fraseologismo posar banyes a algú ['poner los cuernos a alguien'] (DIEC, s. v. banya).

${ }^{51}$ En el mapa 263 (Banya), el ALMAR divide el territorio estudiado (la región alicantina de la Marina) en dos términos: qüerno y banya; a la zona de este último pertenecen las dos localidades de dicho territorio, Benialí y Calp, contempladas en el ALPI.

${ }^{52}$ Este apelativo aparece, sin ir más lejos, en Els Pastorets (1916) de Josep Maria Folch i Torres (18801950), típica representación popular navideña todavía vigente, bajo distintas adaptaciones, en no pocos pueblos de la geografía catalana. Compárese en Banyeta con Încornoratul ['El cornudo'], designación popular para el diablo en rumano. 
Por otro lado, cabró 53 (38 resultados; cfr. port. cabrão), con el sentido de "[m]arit consent de dona adúltera" (DCVB, s. v. cabró3; cfr. it. becco), resulta la forma más recurrente en todo el dominio $\left(24,3 \%\right.$ del total) ${ }^{54}$ es el principal término en las tres provincias valencianas (24 respuestas); y complementado en Castellón y Valencia por el castellanismo cabrón (9 resultados), por el diminutivo cabrito (en ALCora, Castellón) o por cabrero (en Guardamar, Alicante).

En la definición de cabró como "[m]arit que consent l'adulteri de la muller" (DIEC, s. v. cabró ${ }^{2}$, se alude al esposo "consintiente", aspecto al que remiten las formas (véase para todas ellas DECat, s. v. sentir) consentit (en Bassella, Lérida), consentido (en Pedralba y Dos Aguas, Valencia, ambas de habla castellana) y consintidor (en las castellanohablantes Teresa de Begís, Castellón, y Tuéjar, Valencia). Tal consentimiento es lo que parecen sugerir las expresivas denominaciones cobertora ['tapadera'] (en Bolvir, Gerona), mantellina ['mantilla'] (en El Pinós, Alicante) y mantillón ${ }^{55}$ (en la castellanohablante Teresa de Cofrentes, Valencia). De similar manera, obedece al sentido de 'apocado, pusilánime, falto de coraje' (DLE, s. v. marica ${ }^{2}$ ) la forma maricón (en el castellanohablante Ademuz, Valencia), así como el diminutivo pasqualet (en Santpedor, Barcelona) y la cáustica expresión, también en diminutivo, bon josepet (en Alàs, Lérida), que revela incredulidad ante la inmaculada concepción de María y critica la sumisión de José. Finalmente, en Ciudadela (Menorca), registramos duu unes bones cucales, ${ }^{56}$ gráfica imagen que pondría de manifiesto lo que bien resume el siguiente refrán: El mal del cornudo, él no lo sabe y sábelo todo el mundo (Kleiser 1995: 13, núm. 1.182; cfr. la nota 48).

En lo que se refiere a cugul y colló, se trata de dos formas registradas únicamente en el Rosellón (en Taurinyà y en Salses, respectivamente). La primera,

\footnotetext{
53 "encara que menys usat que en castellà, s'ha usat també en català, especialment amb caràcter pejoratiu (...)" (DECat, s. v. cabra).

${ }^{54}$ Consideramos cada término separadamente, sin tener en cuenta sus posibles variantes. De no ser así, la retahíla cornut, cuernut, qüernut, cornudo, cornuda, lleva cuernos y cornart resultaría la más corriente.

55 "[Manta] Passa com a atribut de gent peresosa o deixada, (...) amb analogies en cast. regional mantés, mantillón, mantudo (...)" (DECat, s. v. manta).

56 "cucales (també clucales) 'rotllanes d'espart que posen davant els ulls de la bèstia que tira la sénia' (mall., men.), amb el qual valor és alteració de *clucalles per dissimilació" (DECat, s. v. cucala).
} 
Dialectologia. Special issue, IX (2021), 69-95.

ISSN: 2013-2247

cugul, ${ }^{57}$ equivale a cuguç5 (cfr. DCVB, s. v. cugul2), "Marit de la dona adúltera" (DIEC, s. v. cuguç); la segunda, colló, sería un cALCo del francés couillon (< lat. vulgar COLEO < lat. CōLĚUs; cfr. it. coglione), que, a partir de significados como 'bobo' y 'cobarde' (TLFi, s. v. couillon), derivaría al de 'cornudo'.

\begin{tabular}{|c|c|}
\hline $\begin{array}{r}\text { Pregunta } \\
\text { Región }\end{array}$ & Cornudo (núm. 731) \\
\hline Huesca (2) & cornut $(2 ; 613,614)$ \\
\hline Zaragoza (2) & cornut $(1 ; 628)$, cuernut $(1 ; 629)$ \\
\hline Teruel (3) & cornut $(2 ; 633,634)$, cabró $(\mathbf{1} ; 634)$ \\
\hline Andorra (1) & banyut $(1 ; 700)$ \\
\hline Rosellón (7) & $\begin{array}{l}\text { cornut }(\mathbf{5} ; \mathbf{7 0 1}, \mathbf{7 0 4 ,} 705, \mathbf{7 0 6}, \mathbf{7 0 7}), \\
\text { cugul }(\mathbf{1} ; \mathbf{7 0 2}) \text {, colló }(\mathbf{1} ; \mathbf{7 0 3})\end{array}$ \\
\hline Lérida (23) & $\begin{array}{c}\text { banyut }(\mathbf{7} ; 711,713,714,716,717,718,720) \\
\text { cabró }(\mathbf{5} ; 711,714,715,716,721) \\
\text { cornut }(\mathbf{4} ; 709,710,715,716), \text { cornart }(2 ; 708,709), \\
\text { banut }(2 ; 710,712), \text { bon josepet }(\mathbf{1} ; 713), \\
\text { consentit }(\mathbf{1} ; 716), \text { que porta banyes }(\mathbf{1} ; 719)\end{array}$ \\
\hline Gerona (15) & $\begin{array}{l}\text { banyut }(7 ; 722,723,726,727,728,729,730), \\
\text { cabró }(4 ; 722,724,726,731) \\
\text { cornut }(3 ; 724,725,727) \text {, cobertora }(\mathbf{1} ; 722)\end{array}$ \\
\hline Barcelona (12) & $\begin{array}{c}\text { banyut }(\mathbf{7} ; \mathbf{7 3 3}, \mathbf{7 3 5}, \mathbf{7 3 6}, \mathbf{7 3 7}, \mathbf{7 3 8}, \mathbf{7 3 9}, \mathbf{7 4 0}) \\
\text { cabró }(\mathbf{2} ; \mathbf{7 3 5}, \mathbf{7 3 8 )} \text {, cornut }(\mathbf{1} ; \mathbf{7 3 4}) \\
\text { pasqualet }(\mathbf{1} ; \mathbf{7 3 4}), \text { que les porta llargues }(\mathbf{1} ; \mathbf{7 3 4})\end{array}$ \\
\hline Tarragona (9) & $\begin{array}{c}\text { banyut }(5 ; 741,744,745,746,748) \\
\text { cornut }(2 ; 747,749), \text { bainyut }(2 ; 742,743)\end{array}$ \\
\hline Castellón (23) & 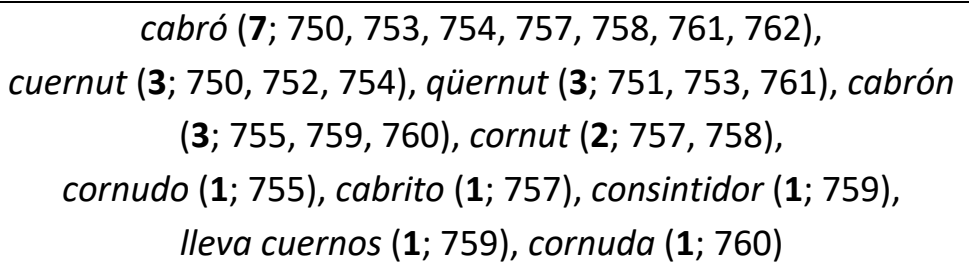 \\
\hline
\end{tabular}

${ }^{57}$ Cugula ['cizaña'] deriva del antiguo cogul o cugul. Según nos apunta Coromines (DECat, s. v. cucut): “L'aplicació popular s'explica fàcilment, perquè així com la femella del cugul o cucut pon els ous, i deixa que covin els seus petits, en el niu, casa o paratge dels altres ocells, la planta cugula fa créixer les seves espigues en la terra del blat, la civada o els altres cereals" (cfr. la glosa del PALDC, mapa 710, La cugula). 58 "en català antic es va dir cogul, provinent del II. CUCŪLUS, fins als Ss. XVI i XVII; una altra variant és el fr. cocu, que abans es digué del cucut i després s'aplicà només a l'home enganyat per la dona; i una altra, el cat. ant. cuguç que no està documentat més que amb aquesta aplicació" (DECat, s. v. cucut). 


\begin{tabular}{|c|c|}
\hline Valencia (33) & $\begin{array}{c}\text { cabró }(\mathbf{9} ; 765,769,770,772,774,775,778,779,780), \\
\text { cuernut }(\mathbf{8} ; 765,769,770,772,775,778,779,780), \\
\text { cabrón }(\mathbf{6} ; 763,764,768,771,773,776), \\
\text { cornudo }(\mathbf{4} ; 763,768,771,773), \text { consentido }(\mathbf{2} ; 768,773) \text {, } \\
\text { maricón }(\mathbf{1} ; 763), \text { consintidor }(\mathbf{1} ; 764), \\
\text { banyut }(\mathbf{1} ; 774), \text { mantillón }(\mathbf{1} ; 776)\end{array}$ \\
\hline Alicante (18) & $\begin{array}{c}\text { cabró }(8 ; 781,782,783,784,785,787,788,790), \\
\text { cuernut }(\mathbf{5} ; 781,782,787,788,790) \\
\text { cornut }(2 ; 784,785) \text {, que porta banyes }(\mathbf{1} ; 784), \\
\text { mantellina }(\mathbf{1} ; 785) \text {, cabrero }(\mathbf{1} ; 790)\end{array}$ \\
\hline Baleares (8) & $\begin{array}{c}\text { banyut }(\mathbf{5} ; 791,792,794,802,803) \\
\text { cabró }(2 ; 794,803) \text {, duu unes bones cucales }(\mathbf{1} ; 802)\end{array}$ \\
\hline
\end{tabular}

Tabla 2. Resultados léxicos del $A L P I$ para el cornudo (núm. 731) en el dominio lingüístico catalán y en el castellano de tierras valencianas.

\subsection{Glotón (núm. 734; 214 resultados) ${ }^{59}$}

Cuenta la leyenda que, en cierta ocasión, los monjes del monasterio cisterciense de Poblet (Tarragona), para combatir una gran mortandad que padecían, imploraron la ayuda de un reputado doctor, quien no tardó en colegir que el origen del problema residía en la desmedida glotonería de los clérigos; les conminó, pues, en primer lugar, a renunciar al aperitivo en forma de perdiz que acompañaba cada comida. Ofendidos por tan tajante medida, los monjes se reunieron en capítulo y, desoyendo los consejos médicos, acordaron seguir A perdiu per barba, i peti qui peti! ${ }^{60}$ ['iA perdiz por barba, y caiga quien caiga!'] (Amades 1985: 14). Aquellos monjes honraban sin duda alguna el término glotón (DLE, s. v.), "Que come con exceso y con ansia", ${ }^{61}$ aunque sin llegar a los excesos de Gargantúa, el tragaldabas por antonomasia de la literatura, ${ }^{62}$ quien, por

\footnotetext{
${ }^{59}$ Véase el mapa 1824 (El golafre) del ALDC y, para la franja catalanohablante de Aragón, la lámina n.은 1.339 / mapa n.o 1.128 (Glotón) del ALEANR.

${ }^{60}$ Una anécdota similar, con libra carnicera (equivalente a 36 onzas de carne, es decir, a unos 1.035 grs.) en vez de perdiz, y con los monjes del monasterio de Veruela (Zaragoza) como protagonistas, finaliza con el refrán iA carnicera por barba, y caiga el que caiga! (cfr. Iribarren 1994: 156-157 y Kleiser 1995: 328, núm. 28.991).

${ }^{61}$ En la concepción de Dante, a diferencia de los usureros (Inferno, Canto XVII), culpables de haber incurrido en un pecado de maldad o antinatural, los golosos pecaron porque se dejaron llevar por el instinto, concretamente, "per la dannosa colpa de la gola" (Canto VI, v. 53); por lo tanto, en el mundo infernal, ocupan un lugar en el tercer círculo mucho más apacible que el de los usureros, ubicados en el séptimo.

${ }^{62}$ En nuestro imaginario popular, destaca la figura de Papús, protagonista del fraseologismo Comer más que Papús; de él nos cuenta Iribarren (1994: 198): “Contra lo que pudiera suponerse, Papúss fue un célebre ayunador, y precisamente por perseverar sin comer muchos días, suponía la gente que aquel
} 
poner un solo ejemplo, desayunaba hermosas morcillas fritas, chuletas asadas, jamón, aves y suculentas sopas monjiles (Gargantua, Cap. XXI).

De los 214 resultados obtenidos, la forma normativa golafre ${ }^{63}$ (12 resultados; DIEC, s. v.; cfr. ALDC, mapa 1824) es la más recurrente tanto en Gerona como en el Rosellón, ${ }^{64}$ y aparece ocasionalmente en Barcelona (Sant Bartomeu del Grau y Llinars del Vallès) y en Tarragona (Falset). Asimismo, otras denominaciones derivadas de gola (DECat, s. v.) son: golós (10 resultados; cfr. port. guloso o it. goloso), registrado en el Rosellón, Gerona, Tarragona y Zaragoza; golot (en Formiguera, el Rosellón); golut (17 resultados; cfr. fr. goulu), forma preferente en Barcelona, bien representada en Lérida y Tarragona, y documentada en Turís (Valencia) y en Taurinyà (el Rosellón); goludo (en el castellanohablante Azuébar, Castellón); guló (en Guardamar, Alicante); y golifart (en Banyuls, el Rosellón), compuesto a partir de gola y fart, con el que pasamos de la familia léxica de la gula a la del hartazgo: fart ['harto'] (DECat, s. v. farcir) resulta el término más habitual del dominio catalán (a pesar de contar únicamente con 22 respuestas, es decir, un 10,3\% del total), ${ }^{65}$ muy mayoritario en Tarragona, con nutrida representación en Barcelona y Lérida, ${ }^{66}$ y también presente en Mequinenza (Zaragoza), en Valljunquera (Teruel) y en La Pobla de Benifassà (Castellón). Fartó (19 resultados) es forma circunscrita al ámbito valenciano, ${ }^{67}$ donde, en la provincia de Valencia, resulta la más frecuente; en cuanto a la variante fartón (9 resultados), la atestiguamos en Castellón y en Valencia. Fartanera ${ }^{68}$ (7 resultados) es la única forma registrada en Andorra, documentada en Bolvir (Gerona) y muy extendida en Lérida. Los cinco testimonios de fartís (DECat, s. v. farcir) se ubican en Benabarre y Sant Esteve de

hombre, una vez terminados sus terribles ayunos, se pondría a comer como una fiera. Papúss se exhibió en Madrid y en muchas capitales españolas en el último año del siglo XIX".

63 "mot antic i propi del català, relacionat amb GOLA" (DECat, s. v. gola). Más allá de la anterior premisa, cualquier suposición etimológica resulta meramente hipotética.

${ }^{64}$ En este último caso, ex aequo con golós.

${ }^{65}$ De los tres tipos humanos estudiados, el glotón es el que ostenta más variedad léxica, por cuyo motivo la denominación más habitual, fart, apenas sobrepasa el $10 \%$. Como muestra de dicha riqueza léxica, véase, por ejemplo, el mapa 506 (Pafart) del ALDT, citado en las Conclusiones del presente artículo.

${ }^{66}$ En Pont de Suert (Lérida), espigamos la expresión bou fart ['buey harto'].

67 "Fartaner 'el qui se sol atipar massa', en lloc del qual diuen fartó en val." (DECat, s. v. farcir). Sin dejar el ámbito gastronómico, fartó es conocidísimo, en la Comunidad Valenciana, en la acepción de "Barreta d'una pasta semblant a la de l'ensaïmada, feta de farina, aigua o llet, rent, ous, oli i sucre, que es menja especialment mullada en orxata" (DNV, s. v. fartó $)^{2}$.

68 "Persona amiga de menjar molt" (DIEC, s. v. fartaner, $-a)$. 
Llitera (Huesca), en Maella (Zaragoza), en Clariana (Lérida) y en Santpedor (Barcelona). Asimismo, localizamos fartera ${ }^{69}$ en Biar y en Calp (Alicante), y fartana ${ }^{70}$ (DECat, s. v. farcir), en València d’Àneu y Bassella (Lérida). Enumeramos ALFabéticamente, a continuación, una serie de formas de la familia léxica de fart que obtuvieron un único resultado: afartant (en Sant Joan Baptista, Ibiza), fartaner ${ }^{71}$ (en Senterada, Lérida), fartaor (en Moncofa, Castellón), fartegàs ${ }^{72}$ (en Blanes, Gerona; DECat, s. v. farcir), fartonàs (en Rafaelbunyol, Valencia), fartonasso (en Moixent, Valencia), fartós ${ }^{73}$ (en El Campello, Alicante) y massafart ${ }^{74}$ (en Rialb, Lérida).

A renglón seguido, citamos algunas designaciones relacionadas con el acto de comer: menjador (en Eivissa, Ibiza; cfr. it. mangione o rum. mâncăcios), menjaire (en Campdevànol, Gerona), comedor (en la castellanohablante Pedralba, Valencia) y comilón (en Crevillent, Alicante; cfr. port. comilão). Un grado más de intensidad lo introduce zampador (en el castellanohablante Ademuz, Valencia) y los múltiples, y habituales, derivados de tragar: ${ }^{75}$ tragó (17 resultados) resulta mayoritario en Alicante, muy corriente en Valencia, y se documenta en Sant Esteve de Llitera (Huesca), en Vistabella del Maestrat y Moncofa (Castellón), así como en Mahón (Menorca); localizamos tragón (17 resultados) en las tres provincias de Aragón, mayoritariamente en Castellón, de manera habitual en Valencia y, puntualmente, en Crevillent (Alicante) y en Ciudadela (Menorca). Igualmente, testimoniamos tragador en Aguaviva (Teruel) y en Tuéjar (Valencia), de habla castellana; $\operatorname{dragador}^{76}$ (DCVB, s. v.), en Pont de Suert (Lérida); tragante, en ALCora (Castellón); y tragabales, ${ }^{77}$ en Aín (Castellón).

\footnotetext{
${ }^{69}$ El DCVB (s. v. fartera ${ }^{2}$ ) registra el término en las dos localidades del ALPI (Biar y Calp), a las que añade Pego, en la misma provincia de Alicante.

${ }^{70}$ También documentado en València d'Àneu por el DCVB (s. v. fartana).

${ }^{71}$ Véase la nota 67.

${ }^{72}$ Localizado también en Blanes por el DCVB (s. v. fartegàs).

${ }^{73}$ Sinónimo de fartaner según el DCVB (s. v. fartós).

${ }^{74}$ Es decir, "Golafre" (DCVB, s. v. massafart).

75 "Devorar; menjar excessivament o molt de pressa" (DCVB, s. v. tragar).

${ }^{76}$ Dragar es variante formal de tragar (DCVB, s. v. tragar y dragar); de hecho, según Coromines (DECat, s. v. dragar y tragar), la forma propiamente catalana sería dragar, "com a derivat de DRAC, amb el sentit primitiu de 'devorar com un drac famolenc"' (DECat, s. v. tragar).

${ }^{77}$ El DCVB (s. v. tragabales) también lo localiza en Aín con el sentido de 'Golafre, gran menjador'. Compárese con el español tragaldabas; no en balde, Coromines (DECat, s. v. tragar) considera tragabales castellanismo.
} 
Por otro lado, en fam ['hambre'] se vinculan las soluciones afamat ${ }^{78}$ (en Salses, el Rosellón; y en Agullana y Anglès, Gerona; cfr. it. affamato), mort de fam (en Quart de Poblet, Valencia) y té fam calina ${ }^{79}$ (en Ciudadela, Menorca); en gana ['hambre'], la designación homónima registrada en Agullana (Gerona); en tripa, tripero (en Sóller, Mallorca) y traput (en Bot, Tarragona; DECat, s. v. tripa); en profit ['provecho'], profitós $^{80}$ (en Benilloba y Benialí, Alicante); en tibar ['estirar'] (DECat, s. v.), tip (en Belllloc d'Urgell y Mont-roig de Sió, Lérida); en barra, con el sentido de 'mandíbula' (DIEC, s. v. barra $^{10}$ ), barrusser $^{81}$ (en Rialb, Lérida); y en embut ['embudo'] (DECat, s. v. embut), embuder (11 resultados; localizado en los dos puntos de Teruel, habitual en Castellón y Valencia, y documentado en Calp, Alicante).

La codicia, que en el primer apartado nos remitía a la acumulación desmedida de riquezas (cfr. § 2.1), puede derivar también hacia la comida, como demuestran las siguientes denominaciones: afanós, en Maella (Zaragoza), y tres de ámbito alicantino, gobiós y gomiós ${ }^{82}$ (en Benilloba), y gubiós ${ }^{83}$ (en Benialí). Con similar motivación semántica, anotamos envejós, en El Pinós y Guardamar (Alicante) y recelós, en Oropesa del Mar (Castellón).

Algunas designaciones se refieren a la voracidad animal; así, afram ${ }^{84}$ (< feram ['salvajina']), en Taurinyà (el Rosellón) y brúfol ['búfalo'], en Beniopa (Valencia); o una serie de aves: el buitre, castellanismo (en catalán, voltor) registrado en Vilar de Canes (Castellón) y en Llanera de Ranes (Valencia), que nos recuerda la expresión Comer como un buitre (Iribarren 1994: 197); el gaús ['búho real'], en Senet y Pont de Suert (Lérida); el gamarús ['cárabo'], en Bolvir (Gerona); y el avestruz, en el caso del término

\footnotetext{
${ }^{78}$ El DECat (s. v. fam) señala que, en vez de famolenc, "en cat. central i ross., avui es diu més aviat afamat".

${ }^{79}$ Deturpación de canina que el DCVB (s. v. fam) localiza como dialectalismo en Mallorca y Menorca.

${ }^{80}$ Ubicado, en el sentido de 'Golafre, que menja excessivament', en Benilloba y en la Vall de Gallinera por el DCVB (s. v. profitós $\left.{ }^{3}\right)$.

${ }^{81}$ Véanse el DECat (s. v. barra) y el DCVB (s. v. barrusser).

${ }^{82}$ El DCVB (s. v. gobiós) sitúa gobiós en Benilloba y remite al castellanismo gomiós ['codicioso'] (DCECH, s. v. gomia), "Que té gòmia; cobejós, insaciable (val.)". "Gobiós (...) sembla ser el mateix que el cast. agobioso" (DECat, s. v. gobi).

${ }^{83}$ También el DCVB (s. v. gubiós) lo ubica en Benialí y lo define como "fartaner, golafre".

84 "Golut, que menja molt (Conflent)" (DCVB, s. v. afram²). Véase también DECat (s. v. fer), Camps \& Botet (2013: 28), y compárese con la expresión española Comer como una fiera, que aparece en la citación de Iribarren transcrita en la nota 62.
} 
bestrús (en Llo, el Rosellón), donde la voracidad del mismo se junta con su mítica capacidad de digerirlo todo, incluso el hierro.

En los anteriormente citados gaús y gamarús, coincidirían los sentidos traslaticios de 'bobo' y 'glotón' ${ }^{85}$ No son, sin embargo, los únicos casos de estupidez rayana en irracional glotonería; pensemos en matapà $^{86}$ (en València d'Àneu, Lérida); en galifardeu ${ }^{87}$ (en Organyà, Lérida, y en Bolvir, Gerona), con las variantes galifarder (en Bassella y Clariana, Lérida) y galifardero (en Alàs y Organyà, Lérida); y en tou ${ }^{88}$ (en Alàs, Lérida).

Completamos este apartado con las formas desolut ${ }^{89}(<$ disolut $<$ esp. disoluto) (en Castelló de Farfanya, Lérida), drupón (< dropo) (en El Pinós, Alicante), y tres términos de incierta motivación semántica: galera $^{90}$ (en Bolvir, Gerona), màrfega ${ }^{91}$ (en Campdevànol, Gerona) y martagón (en Teresa de Cofrentes, Valencia, de habla castellana).

\begin{tabular}{|c|c|}
\hline $\begin{array}{r}\text { Pregunta } \\
\text { Región }\end{array}$ & Glotón (núm. 734) \\
\hline Huesca (4) & fartís $(2 ; 613.614)$, tragó $(\mathbf{1} ; 614)$, tragón $(\mathbf{1} ; 613)$ \\
\hline Zaragoza (5) & $\begin{array}{l}\text { afanós }(1 ; 629), \text { fart }(1 ; 628), \text { fartís }(1 ; 629) \text {, } \\
\text { golós }(1 ; 628) \text {, tragón }(1 ; 629)\end{array}$ \\
\hline Teruel (5) & $\begin{array}{l}\text { embuder }(2 ; 633,634), \text { fart }(1 ; 633), \\
\text { tragador }(1 ; 634), \text { tragón }(1 ; 634)\end{array}$ \\
\hline Andorra (1) & fartanera $(\mathbf{1} ; 700)$ \\
\hline Rosellón (14) & $\begin{array}{c}\text { golafre }(\mathbf{4} ; \mathbf{7 0 3}, \mathbf{7 0 4}, \mathbf{7 0 5}, \mathbf{7 0 6}) \text {, golós }(\mathbf{4} ; \mathbf{7 0 3}, \mathbf{7 0 4}, \mathbf{7 0 5}, \mathbf{7 0 7}), \\
\text { afamat }(\mathbf{1} ; \mathbf{7 0 3}) \text {, afram }(\mathbf{1} ; \mathbf{7 0 2}) \text {, bestrús }(\mathbf{1} ; \mathbf{7 0 5}), \\
\text { golifart }(\mathbf{1} ; \mathbf{7 0 7}), \text { golot }(\mathbf{1} ; \mathbf{7 0 1}) \text {, golut }(\mathbf{1} ; \mathbf{7 0 2})\end{array}$ \\
\hline
\end{tabular}

\footnotetext{
${ }^{85}$ Para gaús, véase el $D C V B$ (s. v.). En el caso de gamarús, este mismo diccionario únicamente registra el sentido de 'bobo', de donde aventuramos que derivaría el de 'glotón'.

${ }^{86}$ Según el DCVB (s. v. matapà), "Beneitot, home inútil per escassesa mental"; la misma fuente lo localiza en la Vall d'Àneu, Solsona, Vic y Montblanc.

87 "alteració de GALAVARDEU, antic i encara valencià, per influència de galifa (variant de califa) 'emperador, musulmà', que popularment s'usa amb el sentit de 'persona poc recomanable, trapella temible" (DECat, s. v. galifardeu). El DCVB (s. v.) añade a la anterior caracterización la "manca de seny" ['falta de buen juicio'].

${ }^{88}$ Con el sentido figurado de '[f]luix d'enteniment; fàcil d'enganyar' (DCVB, s. v. tou ${ }^{4}$ ), teniendo en cuenta que "el sentit antic i més propi fou 'buit de dins"' (DECat, s. v. tou).

${ }^{89}$ Según el $D C V B$ (s. v. desolut), que lo localiza en Balaguer: "Golut, que menja molt i de pressa".

${ }^{90}$ Acaso relacionado con el sentido de 'Capesflorat, home de baixa moralitat' (DCVB, s. v. galera ${ }^{14}$ ).

${ }^{91}$ Véase el DCVB (s. v. màrfega²): "Dona grossa i malgirbada".
} 


\begin{tabular}{|c|c|}
\hline Lérida (34) & 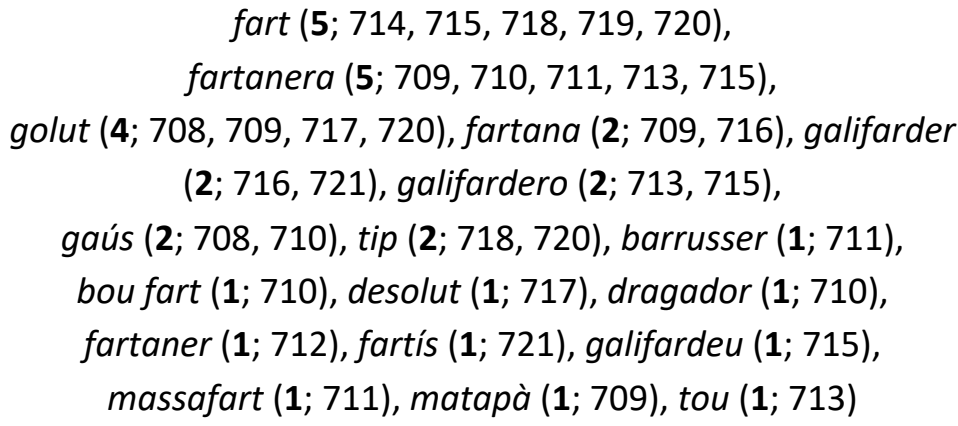 \\
\hline Gerona (18) & $\begin{array}{l}\text { golafre }(5 ; 723,726,727,729,730), \text { golós }(3 ; 724,728,730), \\
\text { afamat }(2 ; 725,729) \text {, fartanera }(1 ; 722) \text {, fartegàs }(1 ; 731), \\
\text { galera }(1 ; 722), \text { galifardeu }(1 ; 722), \text { gamarús }(1 ; 722), \\
\text { gana }(1 ; 725), \text { màrfega }(1 ; 723), \text { menjaire }(1 ; 723)\end{array}$ \\
\hline Barcelona (17) & $\begin{array}{l}\text { golut }(\mathbf{8} ; 732,733,734,735,736,737,738,740), \\
\text { fart }(6 ; 734,735,736,737,739,740) \\
\text { golafre }(2 ; 733,738), \text { fartís }(\mathbf{1} ; 734)\end{array}$ \\
\hline Tarragona (15) & $\begin{array}{l}\text { fart }(\mathbf{8} ; 741,742,743,744,745,746,748,749), \\
\text { golut }(3 ; 741,743,748), \text { golós }(2 ; 746,749), \\
\text { golafre }(\mathbf{1} ; 744), \text { traput }(\mathbf{1} ; 747)\end{array}$ \\
\hline Castellón (32) & 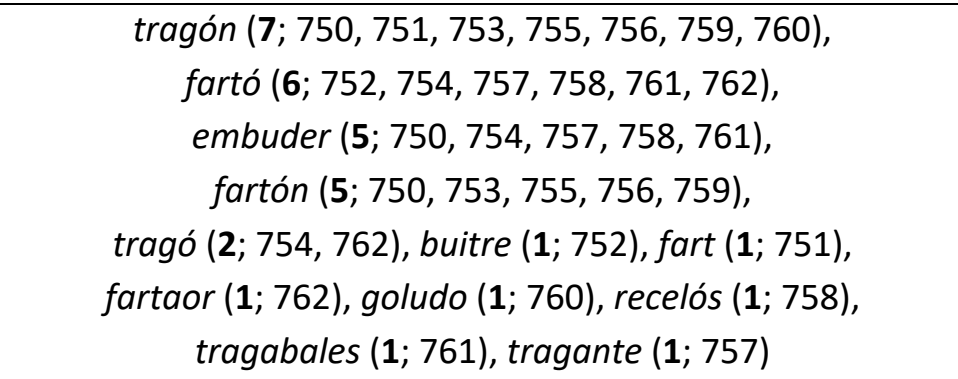 \\
\hline Valencia (37) & $\begin{array}{c}\text { fartó }(9 ; 765,769,770,772,774,775,778,779,780), \\
\text { tragó }(6 ; 765,769,770,774,775,779), \\
\text { tragón }(5 ; 763,766,768,771,776), \\
\text { fartón }(4 ; 763,766,771,773) \text {, embuder }(3 ; 765,778,780), \\
\text { buitre }(1 ; 778), \text { brúfol }(1 ; 779), \text { comedor }(1 ; 768), \\
\text { fartonàs }(1 ; 769) \text { fartonasso }(1 ; 780), \text { golut }(1 ; 772), \\
\text { martagón }(1 ; 776), \text { mort de fam }(1 ; 770), \\
\text { tragador }(1 ; 764), \text { zampador }(1 ; 763)\end{array}$ \\
\hline Alicante (26) & $\begin{array}{c}\text { tragó }(7 ; 781,782,783,784,785,787,790), \\
\text { fartó }(4 ; 781,782,783,788) \text {, envejós }(2 ; 785,790) \\
\text { fartera }(2 ; 781,784), \text { profitós }(2 ; 782,783) \text {, comilón }(1 ; 788) \text {, } \\
\text { drupón }(1 ; 785) \text {, embuder }(1 ; 784) \text {, fartós }(1 ; 787), \\
\text { gobiós }(1 ; 782), \text { gomiós }(1 ; 782) \text {, gubiós }(1 ; 783), \\
\text { guló }(1 ; 790) \text {, tragón }(1 ; 788)\end{array}$ \\
\hline Baleares (6) & $\begin{array}{l}\text { tragón }(1 ; 802) \text {, tragó }(1 ; 803) \text {, afartant }(1 ; 791) \text {, } \\
\text { tripero }(1 ; 794), \text { menjador }(1 ; 792) \text {, té fam calina }(1 ; 802)\end{array}$ \\
\hline
\end{tabular}

Tabla 3. Resultados léxicos del ALPI para el glotón (núm. 734) en el dominio lingüístico catalán y en el castellano de tierras valencianas. 


\title{
3. Conclusiones
}

\begin{abstract}
"[El $A L P I]$ es historia de las variedades rurales románicas peninsulares y baleares del siglo $x x$, sobre todo de su primera mitad, con la importancia que tiene documentarlas en un siglo en el que sufrieron cambios sustantivos como resultado de los otros grandes cambios demográficos, sociales y culturales - que se dieron en los territorios que abarca" (García Mouton 2012: 274).
\end{abstract}

Ciertamente, "un atlas es un archivo fidedigno de cómo hablaban los informantes que se encuestaron para hacerlo" (García Mouton 2007: 344), es decir, "una fotografía de la lengua viva" (Sanchis Guarner 1953: 27); en ese sentido, "[e]l ALPI (...) es espejo de una cultura popular en extinción" (Sousa 2010: 254), lo cual certifica su interés como testimonio histórico de gran calado.

Una vez presentados los resultados léxicos en catalán de los tres tipos humanos objeto del estudio, el usurero, el cornudo y el glotón, recabados de las fichas del ALPI, permítasenos un inocente, pero creemos que muy significativo, divertimento, consistente en reformular la primera parte de nuestro título ("De usureros, cornudos y glotones") en base a los tres términos más frecuentes del ámbito catalanohablante: "De escanyapobres, cabrons y farts". Estirando del hilo, si quisiéramos ser más precisos y nos centráramos en las denominaciones más usuales de la Comunidad Valenciana, la formulación cambiaría notablemente: "De usureros, cabrons y fartons"; y si trasladáramos nuestro interés a Cataluña, resultaría otro título bien diferente: "De escanyapobres, banyuts y farts". Si, para finalizar nuestro experimento, decidiéramos centrarnos en las provincias de Lérida y Gerona, obtendríamos dos resultados que no coincidirían ni entre sí ni con ninguno de los tres anteriores: "De usurers, banyuts y farts" y "De escanyapobres, banyuts y golafres", respectivamente. Nuestro inocuo divertimento nos permite demostrar que ninguno de los tres términos más representativos del dominio catalán llega a una cuarta parte de los resultados totales: escanyapobres $(21,5 \%)$, cabrons $(24,3 \%)$ y farts $(10,3 \%) .{ }^{92}$ Ello significa que en más

\footnotetext{
92 Cfr. la nota 65.
} 
del $75 \%$ de los casos se utilizan variantes o formas diferentes, lo cual evidencia un caudal léxico de incALCulable valor.

Además, complementamos el anterior experimento con la consulta al mapa 506 (Pafart) del ALDT (Atles Lingüístic de la Diòcesi de Tortosa), donde encontramos hasta once denominaciones diferentes para el concepto de 'glotón' ${ }^{93}$ (cfr. § 2.3); se trata, por orden ALFabético, de: barrusser, embuder, fart, fartó, fartón, golafre, golut, moltfart, pafart, tragón y tripero. Un verdadero tesoro léxico concentrado en una región, la de la diócesis de Tortosa, habitada por apenas 300.000 personas.

Como venimos intentando demostrar mediante los ejemplos expuestos anteriormente, los datos léxicos del $A L P I$ presentados en este artículo pueden, y deben, completarse (Doctores habet Ecclesia) con otros atlas de ámbito más reducido; así, al igual que hemos aludido repetidamente al $A L D C$ y al $A L E A N R$, no deberíamos olvidar otras obras, como el citado ALDT, el Atles Lingüístic de la Terra ALTA (ALTA), el Atles Lingüístic de la Comunitat Valenciana $(A L C V)^{94}$ o el Atles Lingüístic del Valencià Meridional i l'Alacantí (ALVMA), por citar solo algunas. ${ }^{95}$ En ese sentido, y puesto que nuestro estudio se ha circunscrito al dominio lingüístico del catalán, tenemos muy presentes las reveladoras palabras de Colón (1989: 82): "cuanto más se examina el léxico catalán, con mayor claridad se comprende el papel central que desempeña para el matizado conocimiento del vocabulario de los idiomas vecinos y del de las lenguas románicas en general".

En resumen, el $A L P I$, como todos los atlas citados a lo largo de este artículo, intenta aprehender una oralidad que resultaría inasible mediante otros métodos; un acervo que interesa no solo a la comunidad científica, sino a los hablantes en general, pues, para decirlo con García Mouton (2010: 169), es "un patrimonio que les pertenece". A título conclusivo, no podemos dejar en el olvido una de las obras más curiosas de la literatura rumana: Povestea vorbii ['El cuento de la palabra'] (1847) de

\footnotetext{
${ }^{93}$ De hecho, la expresiva forma pafart ['panharto'] (DCVB, s. v.), que da título al mapa, no se registra en el ALPI.

94 “están pendientes de publicar aún las encuestas hechas entre 1995 y 1997 para el Atl[e]s Lingüístic de la Comunitat Valenciana (ALCV), dirigido por Jordi Colomina, cuyo cuestionario es de 1994, que serán muy interesantes para conocer las características de todas las hablas valencianas, también las del castellano de Valencia, poco estudiadas" (García Mouton 2009: 341).

${ }^{95}$ Para más detalles sobre estos atlas, véase Veny (1998: 118-122).
} 
Anton Pann (c. 1790-1854); una antología poética en la que el autor, no en vano apodado "cel isteţ ca un proverb" ['el avispado como un refrán'], ${ }^{96}$ ensarta un sinfín de refranes y expresiones populares para hablar, precisamente, de la diversa, y siempre sugestiva, tipología humana. ${ }^{97}$ Dicho volumen luce un subtítulo que, a nuestro parecer, bien podría adoptar cualquier atlas: "de la lume adunate [/] şi iarăşi la lume date" ['de la gente recabados [/] y de nuevo a la gente dados'].

\section{Referencias bibliográficas}

AIS = Karl JABERG \& Jakob JUD (1928-1940) Sprach- und Sachatlas Italiens und der Südschweiz / Atlante linguistico ed etnografico dell'Italia e della Svizzera meridionale, 8 vol., Zofingen: Ringier. Consultable en línea: <https://www3.pd.istc.cnr.it/navigAlS-web/>. $A L C=$ Antoni GrIERA (1923-1964) Atlas Lingüístic de Catalunya, 8 vol., Barcelona / Sant Cugat: Polígraf / Abadia de Sant Cugat del Vallès.

$A L C V=$ Jordi COLOMINA (en prensa) Atles Lingüístic de la Comunitat Valenciana, València: Generalitat Valenciana.

ALDC = Joan Veny \& Lídia Pons i GrierA (2016) Atles Lingüístic del Domini Català. Volum VIII, Barcelona: Institut d'Estudis Catalans. Consultable en línea: $<$ https://aldc.espAIS.iec.cat/>.

ALDT = Lluís GIMENo Betí (1997) Atles Lingüístic de la Diòcesi de Tortosa, Barcelona: Institut d’Estudis Catalans, Biblioteca de Dialectologia i Sociolingüística, IV.

ALEANR = Manuel ALVAR, con la colaboración de Antonio LLORENTE, Tomás BUESA \& Elena ALVAR (1979-1983) Atlas lingüístico y etnográfico de Aragón, Navarra y Rioja, 12 vol., Zaragoza \& Madrid: Diputación Provincial de Zaragoza \& CSIC.

ALF = Jules GILLIÉRON \& Edmond EDMONT (1902-1910) Atlas Linguistique de la France, 9 vol., Paris: Honoré Champion. Consultable en línea: <https://eclats.gricad-pages.univgrenoble-alpes.fr/cartodialect_guide_utilisateur/>.

\footnotetext{
${ }^{96}$ Dicha antonomasia aparece en la poesía Epigonii ['Los epígonos'] (v. 18), obra del máximo poeta rumano, Mihai Eminescu (1850-1889).

${ }^{97}$ Por poner un solo ejemplo del inigualable gracejo de Pann, apuntaremos un cuento suyo en el que un tonto de capirote deambula por un parque a la búsqueda de un árbol ni muy alto ni demasiado bajo para colgar a su esposa. ¿El motivo? Muy simple: el marido había observado como ella bostezaba justo después de que lo hiciera un peatón ocasional, y, desconocedor de cuán contagioso resulta el bostezo, dio por sentado que era una señal con la que se citaban para dar rienda suelta a su pasión.
} 
Dialectologia. Special issue, IX (2021), 69-95.

ISSN: 2013-2247

alMAR = Vicent Beltran Calvo \& Teresa Herrero Lloret (2011) Atles lingüístic de la Marina, Pedreguer: Institut d’Estudis Comarcals de la Marina.

ALTA = Pere NAVARRo (1996) Els parlars de la Terra ALTA. 1. Estudi geolingüístic. 2. Atles Lingüístic de la Terra ALTA (ALTA), 2 vol., Tarragona: Diputació de Tarragona.

Alvar, Manuel (1951) Historia y metodología lingüísticas. A propósito del Atlas de Rumanía, Salamanca: Universidad de Salamanca.

ALVMA = Josep TORMO (en curso de elaboración) Atles Lingüístic del Valencià Meridional $i$ I'Alacantí.

AMADES i GELATS, Joan (1985) Refranyer català comentat, Barcelona: Editorial Selecta.

BAStaRdAS, Maria-Reina (2018), "SAnguisūGA", en Ana Cano, Jean Germain \& Dieter Kremer (eds.), Dictionnaire historique de l'anthroponymie romane. Vol. II/2, Berlin: De Gruyter, 348.

CAMPS, Christian \& Renat BOTET (2013) Dictionnaire nord catalan / Diccionari nord català, Canet: Editions Trabucaire.

COLÓN, Germán \& Helmut LÜDTKE (1965) "[Reseña al] Atlas Lingüístico de la Península Ibérica", Vox Romanica, XXIV, 323-335.

CoLóN, Germán (1989) El español y el catalán, juntos y en contraste, Barcelona: Ariel.

DCECH = Joan COROMINAS, con la colaboración de José Antonio PASCUAL (1980-1991) Diccionario crítico etimológico castellano e hispánico, 6 vol., Madrid: Gredos.

$D C V B=$ Antoni M. ALCOVER \& Francesc de B. MoLL (1930-1962) Diccionari català-valenciàbalear, 10 vol., Palma: Editorial Moll. Consultable en línea: <http://DCVB.iecat.net/>.

DECat $=$ Joan COROMINES, con la colaboración de Joseph GuLSOY \& Max CAHNER I GARCIA (19802001) Diccionari etimològic i complementari de la llengua catalana, 10 vol., Barcelona: Curial Edicions Catalanes \& Caixa de Pensions "La Caixa”.

DIEC = INSTITUT D'ESTUDIS CATALANS $\left(2007^{2}\right)$ Diccionari de la llengua catalana. Consultable en línea: <https://dlc.iec.cat/>.

DLE = REAL ACADEMIA ESPAÑolA (2014) Diccionario de la lengua española, Barcelona: Espasa. Consultable en línea: <http://dle.rae.es/>.

DNV = ACADÈMIA VALENCIANA DE LA LLENGUA (2014) Diccionari normatiu valencià. Consultable en línea: <http://www.avl.gva.es/lexicval/>.

GARCía Mouton, Pilar (2007) “Las disciplinas tradicionales (II). Dialectología y geolingüística”, en José Enrique Gargallo Gil \& Maria Reina Bastardas (coords.), Manual de lingüística románica, Barcelona: Ariel, 319-350. 
GARCía Mouton, Pilar (2009) "La investigación geolingüística española en la actualidad", en Dolores Corbella \& Josefa Dorta (eds.), La investigación dialectológica en la actualidad, Santa Cruz de Tenerife: Agencia Canaria de Investigación, Innovación y Sociedad de la Información, 333-346.

García Mouton, Pilar (2010) "El procesamiento informático de los materiales del Atlas Lingüístico de la Península Ibérica de Tomás Navarro Tomás", en Gotzon Aurrekoetxea \& Jose Luis Ormaetxea (eds.), Tools for Linguistic Variation. Supplements of the Anuario de Filología Vasca "Julio de Urquijo", LIII, Bilbao: Universidad del País Vasco, 167-174.

García Mouton, Pilar (2012) “El Atlas Lingüístico de la Península Ibérica (ALPI) como fuente de documentación", en Emilio Montero Cartelle (ed.), Actas del VIII Congreso Internacional de Historia de la Lengua Española, I, Santiago de Compostela: Asociación de Historia de la Lengua Española \& Meubook, 273-276.

GonZÁLEZ GonZÁLEZ, Manuel (1992) “Metodología de los atlas lingüísticos en España”, en Actas del Congreso Internacional de Dialectología / Nazioarteko Dialektologia Biltzarra. Agiriak. IKER 7, Bilbao: Real Academia de la Lengua Vasca-Euskaltzaindia, 151-177.

IRIBARREN, José María (1994) El porqué de los dichos [1.a ed. 1955], Pamplona: Gobierno de Navarra.

KLEISER = MARTínEZ KLEISER, Luis (1995) Refranero general ideológico español [1.a ed. 1953], Madrid: Librería y Casa Editorial Hernando, S.A.

NAVARRo TomÁs, Tomás (1975) "Noticia histórica del ALPI", en Capítulos de Geografía Lingüística de la Península Ibérica, Bogotá: Instituto Caro y Cuervo, 9-21.

PALDC = Joan VeNY (2015) Petit Atles Lingüístic del Domini Català. Volum V, Barcelona: Institut d'Estudis Catalans. Consultable en línea: <https://aldc.espAIS.iec.cat/>.

PANN, Anton (1982) Povestea vorbii [1.a ed. 1847], Bucureşti: Editura Minerva.

PARÉS i PUNTAS, Anna (1999) Tots els refranys catalans, Barcelona: Edicions 62.

REW = Wilhelm MEYER-LÜBKE $\left(1935^{3}\right)$ Romanisches etymologisches Wörterbuch, Heidelberg: C. Winter.

SANCHIS GUARNER, Manuel (1953) "El tesoro dialectal y el Atlas Lingüístico", en La cartografía lingüística en la actualidad y el Atlas de la Península Ibérica, Madrid: CSIC, 26-27.

SOUSA FERNÁNDEZ, Xulio (2010) "Entre el atlas lingüístico y el diccionario. Un diccionario de léxico tradicional a partir de los materiales del ALPI", en Ignacio Ahumada (ed.), Metalexicografía variacional. Diccionarios de regionalismos y diccionarios de especialidad, Málaga: Universidad de Málaga, 237-256. 
Dialectologia. Special issue, IX (2021), 69-95.

ISSN: 2013-2247

TLFi = ATILF - CNRS \& UNIVERSITÉ DE LORRAINE (2004-) Trésor de la Langue FrançAISe informatisé. Consultable en línea: <http://atilf.atilf.fr/>.

VENY i CLAR, Joan (1998) “La geolingüística catalana, ahir i avui”, Caplletra, 25, 109-134. 


\section{Apéndice}

Presentamos, a continuación, una tabla con los 96 lugares del dominio lingüístico catalán estudiados en la red de encuesta del $A L P I$, así como los 15 castellanohablantes de territorio administrativo valenciano (cfr. la nota 4), que, en aras de una mayor claridad, distinguimos en negrita. A fin de facilitar la identificación de los mencionados 111 lugares, se acompañan del pertinente número de referencia, del que nos hemos valido en las tres tablas anteriores, y dicha numeración se presenta en orden ascendente. Téngase en cuenta, como nos apunta González (1992: 166), que "[e]n el ALPI la numeración se hace con tres cifras, en las que la que corresponde a la centena indica la pertenencia a una de las siete zonas en que se dividió la Península Ibérica, y las otras dos identifican el punto dentro de cada una de estas zonas"; la numeración es continua dentro de cada provincia y, por regla general, obedece a los parámetros Norte-Sur y Oeste-Este. En nuestro caso, de los siete sectores anteriormente mencionados, para el ámbito catalanohablante interesan los dos últimos, ${ }^{98}$ es decir, "600 Navarra y Aragón” (7 puntos de encuesta) y "700 Andorra, el Rosellón, Cataluña, Valencia y Baleares"; esta última, por su extensión, rebasa la centena asignada y se introduce en la siguiente en los cuatro últimos puntos, correspondientes a Mallorca (800-801) y a Menorca (802-803).

\begin{tabular}{|c|c|}
\hline \multicolumn{2}{|c|}{$\begin{array}{l}\text { LUGARES DEL DOMINIO CATALÁN (INCLUYENDO LOS } 15 \text { CASTELLANOHABLANTES DE TERRITORIO } \\
\text { ADMINISTRATIVO VALENCIANO) ESTUDIADOS } \\
\text { EN LA RED DE ENCUESTA DEL ALPI }\end{array}$} \\
\hline \multicolumn{2}{|c|}{ HUESCA (612-614) } \\
\hline $\begin{array}{l}\text { 612: La Pobla de Roda } \\
\text { 613: Benabarre }\end{array}$ & 614: Sant Esteve de Llitera \\
\hline \multicolumn{2}{|c|}{ ZARAGOZA (628-629) } \\
\hline 628: Mequinensa (Mequinenza) & 629: Maella \\
\hline \multicolumn{2}{|c|}{ TERUEL (633-634) } \\
\hline 633: Valljunquera & 634: Aiguaviva (Aguaviva) \\
\hline \multicolumn{2}{|c|}{ ANDORRA (700) } \\
\hline \multicolumn{2}{|l|}{ 700: Encamp } \\
\hline \multicolumn{2}{|c|}{ ROSELLÓN (701-707) } \\
\hline $\begin{array}{l}\text { 701: Formiguera } \\
\text { 702: Taurinyà } \\
\text { 703: Salses } \\
\text { 704: Cabestany }\end{array}$ & $\begin{array}{l}\text { 705: Llo } \\
\text { 706: Arles de Tec } \\
\text { 707: Banyuls }\end{array}$ \\
\hline \multicolumn{2}{|c|}{ LÉRIDA (708-721) } \\
\hline $\begin{array}{l}\text { 708: Senet } \\
\text { 709: València d'Àneu } \\
\text { 710: Pont de Suert } \\
\text { 711: Rialb } \\
\text { 712: Senterada }\end{array}$ & $\begin{array}{l}\text { 715: Organyà } \\
\text { 716: Bassella } \\
\text { 717: Castelló de Farfanya } \\
\text { 718: Bell-lloc d'Urgell } \\
\text { 719: Aspa }\end{array}$ \\
\hline
\end{tabular}

98 Los cinco sectores restantes en los que se divide la península son: "100 Galicia”, "200 Portugal”, "300 Asturias, León y Extremadura", "400 Las Castillas y la provincia de Albacete" y "500 Andalucía y la provincia de Murcia". 
Dialectologia. Special issue, IX (2021), 69-95.

ISSN: 2013-2247

\begin{tabular}{|c|c|}
\hline $\begin{array}{l}\text { 713: Alàs } \\
\text { 714: Guàrdia }\end{array}$ & $\begin{array}{l}\text { 720: Mont-roig de Sió } \\
\text { 721: Clariana }\end{array}$ \\
\hline \multicolumn{2}{|c|}{ GERONA (722-731) } \\
\hline 722: Bolvir & 727: Besalú \\
\hline 723: Campdevànol & 728: Bordils \\
\hline 724: Molló & 729: Anglès \\
\hline 725: Agullana & 730: Mont-ras \\
\hline 726: Cadaqués & 731: Blanes \\
\hline \multicolumn{2}{|c|}{ BARCELONA (732-740) } \\
\hline 732: La Valldan & 737: Viladecavalls \\
\hline 733: Sant Bartomeu del Grau & 738: Llinars del Vallès \\
\hline 734: Santpedor & 739: La Granada del Penedès \\
\hline 735: Castellterçol & 740: Cornellà de Llobregat \\
\hline 736: Sant Martí de Sesgueioles & \\
\hline \multicolumn{2}{|c|}{ TARRAGONA (741-749) } \\
\hline 741: Santa Coloma de Queralt & 746: Roda de Berà \\
\hline 742: Vimbodí & 747: Bot \\
\hline 743: Ascó & 748: La Cala de l'Ametlla \\
\hline 744: Falset & 749: Amposta \\
\hline 745: Vila-seca de Solcina & \\
\hline \multicolumn{2}{|c|}{ CASTELLÓN (750-762) } \\
\hline 750: Cinctorres & 757: ALCora \\
\hline 751: La Pobla de Benifassà & 758: Oropesa del Mar \\
\hline 752: Vilar de Canes & 759: Teresa de Begís \\
\hline 753: Peñíscola & 760: Azuébar \\
\hline 754: Vistabella del Maestrat & 761: Aín \\
\hline 755: Castillo de Villamalefa & 762: Moncofa \\
\hline 756: Fanzara & \\
\hline \multicolumn{2}{|c|}{ VALENCIA (763-780) } \\
\hline 763: Ademuz & 772: Turís \\
\hline 764: Tuéjar & 773: Dos Aguas \\
\hline 765: Casinos & 774: Polinyà de la Ribera \\
\hline 766: Marinas & 775: Massalavés \\
\hline 767: Caudete de las Fuentes & 776: Teresa de Cofrentes \\
\hline 768: Pedralba & 777: Anna \\
\hline 769: Rafaelbunyol & 778: Llanera de Ranes \\
\hline 770: Quart de Poblet & 779: Beniopa \\
\hline 771: Godelleta & 780: Moixent \\
\hline \multicolumn{2}{|c|}{ ALICANTE (781-790) } \\
\hline 781: Biar & 786: Monforte \\
\hline 782: Benilloba & 787: El Campello \\
\hline 783: Benialí & 788: Crevillent \\
\hline 784: Calp & 789: Dolores \\
\hline 785: El Pinós & 790: Guardamar \\
\hline \multicolumn{2}{|c|}{ BALEARES (791-803) } \\
\hline 791: Sant Joan Baptista (Ibiza) & 798: Felanitx (Mallorca) \\
\hline 792: Eivissa (Ibiza) & 799: Manacor (Mallorca) \\
\hline 793: Calvià (Mallorca) & 800: Son Servera (Mallorca) \\
\hline 794: Sóller (Mallorca) & 801: Capdepera (Mallorca) \\
\hline 795: Pollensa (Mallorca) & 802: Ciutadella (Ciudadela) (Menorca) \\
\hline 796: Sineu (Mallorca) & 803: Maó (Mahón) (Menorca) \\
\hline 797: Campos (Mallorca) & \\
\hline
\end{tabular}

